\title{
Solver Device for Powdery Drugs
}

\author{
Dalaei Milan M. ${ }^{\oplus}$, Abedi H. A. ${ }^{2}$, Saadatmand V. ${ }^{3 *}{ }^{\circledR}$, Hesa- \\ minia A. ${ }^{4}$
}

\begin{abstract}
Pharmacotherapy is a major treatment method in healthcare centers, and the injection of powdered drugs is among common pharmacotherapy techniques. Medication errors and nosocomial infections are among major health issues in the world. On the other hand, powdered drugs are widely used in hospitals; however, drug mixture is a very time-consuming process. The objective of this invention was to accelerate drug vial mixture, reduce medication errors and nosocomial infections, and save time.

There are different drug mixing devices, each with specific abilities. The present invention not only possesses the abilities of other devices but also can mix drugs [with a diluent] with higher quality and accuracy.

The drug vial mixing device can mix 20 vials at adjustable time and speed with high quality and accuracy. This device is equipped with an infrared system to ensure a complete mixture of powder, and a Bluetooth short range radio system to remotely control all monitoring options of the device. This is a small and simple-to-use device.

The drug vial mixing device can effectively reduce medication errors and nosocomial infections, and save time.
\end{abstract}

Citation: Dalaei Milan M, Abedi H. A, Saadatmand V, Hesaminia A. Solver Device for Powdery Drugs. J Biomed Phys Eng. 2019;9(4):501504. https://doi.org/10.31661/jbpe.v0i0.795.

\section{Keywords}

Cross Infection • Medical Errors • Powders • Drug Compounding

\section{Introduction}

$\mathrm{P}$ harmacotherapy is a major and widely used treatment method in healthcare centers [1]. Injection is a common method for the administration of pharmaceutical products, which are mainly in the form of vaccines and powdered vials that should be used with an appropriate diluent [2]. Powdered vials are known as one of the most widely used drugs in hospitals [3]. Typically, the lack of adherence to therapeutic standards is associated with actual and potential risks for healthcare providers and users, as well as society. According to WHO, some 16,000 million injections are administered each year in developing countries (3-4 injections per person on average), among them more than $90 \%$ are given for therapeutic purposes while $5-10 \%$ are given for preventive services. The prevalence of unsafe injections ranges from $15 \%$ in Eastern Europe to $50 \%$ in Asia. The annual rate of mortality from medical errors is 98,000, out of which 7,000 deaths are due to medication errors [4-5]. Medication errors are the 8th leading cause of mortality in the USA. They affect one in 10 hospitalized patients worldwide [6]. Intravenous injections account for the majority of medication errors. According to Kaushal et al., $61 \%$ of medication errors in hospitals are related to intra-

${ }^{1}$ Nursing Student, Student Research Committee, Jahrom University of Medical Sciences, Jahrom, Iran

${ }^{2}$ Associate Professor,

Ph.D. of Human Physiol-

ogy, Faculty of Medicine,

Research Center for

Noncommunicable Dis-

eases, Jahrom University

of Medical Sciences,

Jahrom, Iran

${ }^{3}$ M.sc. of Critical Care

Nursing, Paramedical

and Faculty Member

of Jahrom University of

Medical Sciences, Jah-

rom, Iran

${ }^{4}$ Nursing Student, Stu-

dent Research Commit-

tee, Jahrom University

of Medical Sciences,

Jahrom, Iran

*Corresponding author:

V. Saadatmand,

M.sc. in Critical Care

Nursing, Paramedical

and Faculty Member

of Jahrom University of

Medical Sciences, Jah-

rom, Iran

E-mail: vahid.saadat60@ gmail.com

Received: 14 June 2017 Accepted: 23 August 2017 
venous injections [7]. According to Anousheh et al., nurses mentioned such factors as inappropriate shifts, insufficient staff and the lack of appropriate equipment and facilities as the causes of medication errors [8]. Given global standards, including USP-797, and since injections are administered into the vein, cerebrospinal fluid, muscle, subcutaneous layers, etc., drug composition and the mixture should be done in a completely sterile setting $[1,2,9$, 10]. Nosocomial infections are among global health issues, which affect both developing and advanced countries [11]. They are seen approximately in $10 \%$ of hospitalized patients, mainly through contact and primarily via the hands of healthcare workers [12]. These infections are among the major causes of mortality and increased rate of complications among hospitalized patients. According to the reports, nosocomial infections affect two million individuals and cause 19,000 deaths annually [13]. Nosocomial infections are among major hospital-related health issues worldwide. Despite great progress in the control and prevention of nosocomial infections, it continues to remain as the most important treatment complication, which significantly causes death and increases medical expenses [14]. The spread of nosocomial infections from one patient to another is often because medical personnel are not adequately trained, contaminated equipment is not carefully sterilized and disinfected, disinfectants are used inappropriately, there is a shortage of healthcare workers, and nurses lack sufficient time [15].

Since there is a high demand for daily injection of powdered drugs in different hospital units, nurses have to spend a lot of time on mixing process, causing a delay in doing other tasks. Therefore, they have to work too quickly to compensate for the delay, which leads to higher probability of making errors. Accordingly, the objective of this invention was to accelerate the drug vial mixture, reduce medication errors and nosocomial infections, and save time.

\section{Material and Methods}

The powdered drug mixing device has two general electronic and mechanical structures. The mechanical structure works based on a vibration mechanism and consists of a plate $\left(15 \times 15 \mathrm{~cm}^{2}\right)$ and various vial holders with different diameters. This plate has two motors opposite to each other to produce vibration in two axes. The electronic system of the device includes a control panel mounted on a $10 \times 20$ $\mathrm{cm}^{2}$ plate. The control panel has 4 keys on four corners of the plate. Key 1 (red) is used to increase the rotation speed and vibration time. Key 2 (black) is used to decrease the rotation speed (down to 10) and vibration. Key 3 (white) is used to signal OK. Key 4 (green) is used to manually start and stop the device by keeping it pushed down and releasing it, respectively. There is a screen $\left(10 \times 2 \mathrm{~cm}^{2}\right)$ in the middle of the control panel to display information. This device is equipped with infrared sensors to detect the correct location of vials. When the sensors are in place, the device starts working until the drug is fully diluted (becomes transparent). It is also equipped with a Bluetooth short range radio module that allows remote control of the monitoring system of the device. This technology allows the control of all four keys remotely. There are four springs mounted on vial holding plate to uniformly distribute vibration across the plate. The device is powered with a power adapter (Figure 1).

\section{Results}

The drug mixing device invented by Yuhua Li (2008) was comprised of a case body, a rotating shaft, a swivel plate and a crank handle. This system works based on a rotating mechanism to dilute medication [16]. Osamu Mizuno, Akinobu Okuda and Toheu Nakamura (2013) invented a drug mixing device that includes a main rotating-base, a sub rotatingbase and a control unit. The main rotating base includes a holding portion to hold medicine and the sub rotating-base includes a holding 


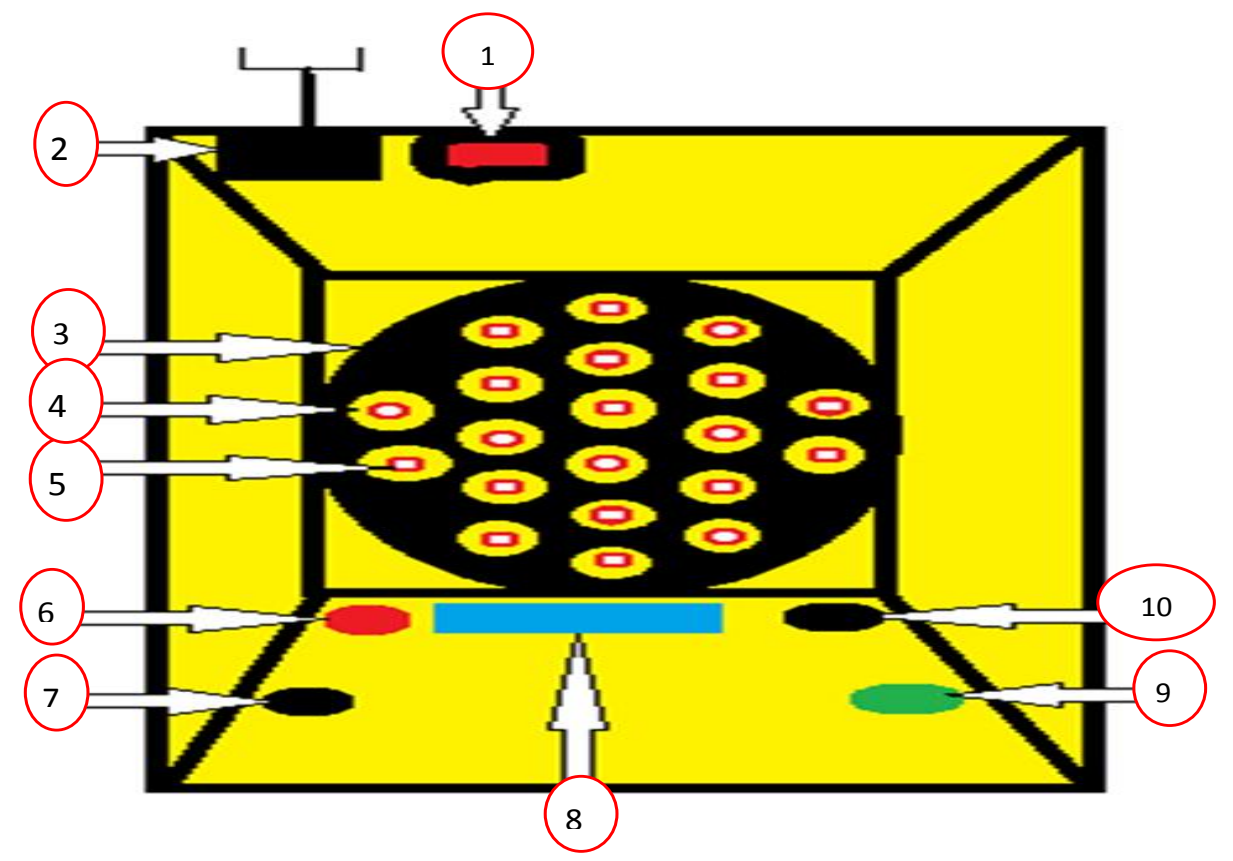

Figure 1: Schematic Powdered Drug Vial Mixing Device

1. Main key on \& off

2. Cable Adapter

3. The main plate placing the vial on it

4. vial placing

5. Infrared

6. The key to increase the engine speed and the time (red key)

7. The key to decrease the engine speed and the time (black key)

8. Monitor screen for showing information

9. Automatic key (Press this key to power up the device and start work without time limits and Off the key machine automatically stops)(green key)

10. To OK the device

portion to hold syringe. Rotating movements place the syringe in a vial, containing powdered drugs, to suck the desired amount of medicine [17]. Klaus Glejboel and Frederiksen Morted Revsgaard (2008) invented a drug mixing and infusion device, which includes a holding portion to hold vial and a reservoir to contain a liquid. Establishment of a connection between these two parts shifts liquid towards vial to dilute the medicine. Then, the medicine moves to infusion outlet in a controlled way [18]. Young-Duck Kwon and Seong Nyeon Kim (2008) invented a drug mixing device for vibrating and rotating a drug vial, containing two or more different powdered drugs to mix them. The drugs mixing device includes a device body, a motor, a vial holder, and a power supply source. The device mixes or dilutes powdered drugs by generating vibration and rotation [19]. Bo Radmer, Louise Charlotte Klok and Gunner Sie (2007) invented a drug mixing device, which includes a holder to hold vials and a reservoir to contain a liquid.

\section{Discussion}

The device starts working when a connection is established between these two parts, and the medicine is mixed with the liquid until it is 
diluted. After the completion of the dilution process, the device is automatically turned off [20]. In addition to these characteristics, our invented device is equipped with an infrared monitoring system to ensure complete solution of the powdered medicine. It is also equipped with a Bluetooth short range radio module to remotely control all monitoring options.

\section{Advantages}

- Several vials can be diluted within a certain time automatically or manually.

- Vibration intensity can be controlled by increasing or decreasing the power of the motor.

- Vibration time can be controlled.

- Bluetooth short range radio module allows remote control of all monitoring options of the device.

- The infrared system allows the device to operate automatically when infrared sensors are in place until the drug is completely diluted (becomes transparent). Then, the device is automatically turned off.

- It is a simple-to-use device.

\section{Acknowledgment}

The Research Department of Jahrom University of Medical Sciences, the Development and Technology Center of Jahrom University of Medical Sciences, Mr. Ali Akbar Shakeri, Mr. Mohammad Naderizadeh and other colleagues are deeply thanked for their collaboration in the conduction of this study.

\section{Conflict of Interest}

\section{None}

\section{References}

1. Gahart B, Nazareno A. Intravenous medications, 27th edition. Elsevier; 2011.

2. Trissel LA. Handbook on injectable drugs. 2003.

3. Delsing J. A new velocity algorithm for singaround-type flow meters. IEEE Trans Ultrason Ferroelectr Freq Control. 1987;34:431-6. doi. org/10.1109/T-UFFC.1987.26963. PubMed PMID: 18291865.

4. Mewshaw MR, White KM, Walrath J. Medical errors: where are we now? Nurs Manage. 2006;37:50-4. PubMed PMID: 17072154.

5. Fry MM, Dacey C. Factors contributing to in- cidents in medicine administration. Part 1. $\mathrm{Br} J$ Nurs. 2007;16:556-8. doi.org/10.12968/ bjon.2007.16.9.23435. PubMed PMID: 17551449.

6. Goeckner B, Gladu M, Bradley J, Garmon SC, Hicks RW. Differences in perioperative medication errors with regard to organization characteristics. AORN J. 2006;83:351-2, 355-62, 365-8. PubMed PMID: 16544856.

7. Kaushal R, Bates DW, Landrigan C, McKenna KJ, Clapp MD, Federico F, et al. Medication errors and adverse drug events in pediatric inpatients. JAMA. 2001;285:2114-20. doi.org/10.1001/ jama.285.16.2114. PubMed PMID: 11311101.

8. Anoosheh M, Ahmadi F, Faghihzadeh S, Vaismoradi $M$. Survey of predisposing causes of working errors in nursing cares from perspective of nurses and their mangers perspectives. Iran Journal of Nursing. 2007;20:25-36.

9. Pharmacopeia U, editor. USP $<$ 797> Guidebook to Pharmaceutical Compounding-Sterile Preparations. United States Pharmacopeial Convention; 2008.

10. Fahimi F, Ariapanah P, Faizi M, Shafaghi B, Namdar $\mathrm{R}$, Ardakani MT. Errors in preparation and administration of intravenous medications in the intensive care unit of a teaching hospital: an observational study. Aust Crit Care. 2008;21:110-6. doi. org/10.1016/j.aucc.2007.10.004. PubMed PMID: 18387813.

11. Masoomi-Asl H. User country care system of hospital infections. Disease Management Center, Tehran; 2006. P. 91.

12. Knox KL, Holmes $A H$. Regulation of antimicrobial prescribing practices-a strategy for controlling nosocomial antimicrobial resistance. International journal of infectious diseases. 2002;6:S8-S13. doi. org/10.1016/S1201-9712(02)90149-9.

13. Petty WC. PACU-Why Hand Washing Is Vital! Journal of Peri Anesthesia Nursing. 2009;24:2503. doi.org/10.1016/j.jopan.2009.05.101.

14. Agarwal M, Thomas P. Prevalence of post-op. nosocomial infection in neurosurgical patients and associated risk factors--a prospective study of 2441 patients. Nurs J India. 2003;94:197-8, 212. PubMed PMID: 15315200.

15. Gould D. Nurses' hand decontamination practice: results of a local study. J Hosp Infect. 1994;28:1530. doi.org/10.1016/0195-6701(94)90149-X. PubMed PMID: 7806865.

16. Yuhua Li Inventors [Internet]. Solution and mixing device of injecting powder medicine: Patent CN201076607 Y (25 Jun 2008). Available from: http://google.com/patents/CN201076607Y?cl=en.

17. Mizuno 0, Okuda A, Nakamura T. Medication mixing device and medication mixing method. Google Patents; 2013.

18. Glejboel K, Frederiksen MR. Drug Mixing and Infusion Device. Google Patents; 2007.

19. Young-Duck Kwon, Seong Nyeon Kim Inventors [Internet]. Drugs mixing device: Patent W02008103004 A1 (28 Aug 2008). Available from: https://encrypted.google.com/patents/ W02008103004A1?cl=ar.

20. Radmer B, Klok LC, Sie G. Drug Mixing Device. Google Patents; 2007. 